\title{
The effect of domain prestige and interlocutors' bilingualism on loanword adaptations ${ }^{1}$
}

\author{
Shiri Lev-Ari, ${ }^{\text {a,b }}$ Marcela San Giacomo ${ }^{c}$ and \\ Sharon Peperkamp \\ a. Max Planck Institute for Psycholinguistics, The Netherlands \\ b. Laboratoire de Sciences Cognitives et Psycholinguistique \\ (ENS - PSL Research University / EHESS / CNRS), France \\ c. Universidad Nacional Autónoma de México
}

\begin{abstract}
There is great variability in whether foreign sounds in loanwords are adapted, such that segments show cross-word and cross-situational variation in adaptation. Previous research proposed that word frequency, speakers' level of bilingualism and neighborhoods' level of bilingualism can explain such variability. We test for the effect of these factors and propose two additional factors: interlocutors' level of bilingualism and the prestige of the donor language in the loanword's domain. Analyzing elicited productions of loanwords from Spanish into Mexicano in a village where Spanish and Mexicano enjoy prestige in complementary domains, we show that interlocutors' bilingualism and prestige influence the rate of sound adaptation. Additionally, we find that speakers accommodate to their interlocutors, regardless of the interlocutors' level of bilingualism. As retention of foreign sounds can lead to sound change, these results show that social factors can influence changes in a language's sound system.
\end{abstract}

Existe una gran variación en la forma en la que los sonidos ajenos a una lengua receptora se adaptan en préstamos lingüísticos, de tal forma que los segmentos muestran variación en la adaptación a través de diferentes tipos de palabras y entre distintos tipos de situaciones. Investigaciones previas proponen que la frecuencia de palabra y el nivel de bilingüismo, tanto individual como el de la localidad de los hablantes, pueden explicar dicha variabilidad. Probamos el efecto de estos factores y propusimos dos variables adicionales: el nivel de bilingüismo de los interlocutores y el prestigio de la lengua donante en el ámbito de los préstamos. Al analizar una muestra de producción de préstamos del español en el mexicano de Tagcotepec, una comunidad donde ambas lenguas tienen prestigio en ámbitos complementarios, mostramos que el bilingüismo de los interlocutores y el prestigio influencian el porcentaje de adaptación de sonidos. Asimismo, encontramos que los hablantes adaptan su forma de hablar a sus interlocutores, según el nivel de bilingüismo. Puesto que retener un sonido ajeno en la lengua receptora puede llevar al cambio 
lingüístico, estos resultados muestran que los factores sociales pueden influenciar los cambios en el sistema de sonidos de una lengua determinada. [Spanish]

KEYWORDS: Language contact, language change, borrowing, bilingualism, sound adaptation, Mexicano

\section{INTRODUCTION}

A high proportion of the vocabulary of many languages consists of words which originated in a different language, namely, loanwords. Ballet, alcohol and pizza are a few examples of words that were borrowed into English. Since languages differ in their sound systems, loanwords commonly contain sounds that the borrowing language does not have. Often, the foreign sounds are adapted to existing sounds in the borrowing language. For instance, when French borrowed from English the term Happy Hour, the /h/ in happy was deleted, because French has no /h/. Yet other times the foreign sounds are retained, as the affricate $/ \mathrm{d} 3 /$ in the borrowing of jeans into French. Ultimately, retention of foreign segments can lead to sound change in the borrowing language (Boretzky 1991; Lee 2013). For example, the phonemic distinction between /f/ and /v/ in English is a result of large-scale borrowing of words with word-initial /v/ from French into Old English following the Norman invasion (Winford 2005: 134). In this study, we will show how social factors influence whether speakers adapt or retain foreign sounds in loanwords.

Some of the variability in whether or not a segment is adapted seems to depend on the segment itself, as some segments are almost categorically adapted while others rarely are. German, for instance, has neither nasal vowels nor the voiced fricative $/ 3 /$; in loanwords from French, nasal vowels are systematically adapted, but $/ 3 /$ is typically retained (Wiese 1996). It has been proposed that such variability in sound adaptation might reflect differences in articulatory ease (Ussishkin and Wedel 2003), in perceptual discriminability (Peperkamp, Vendelin and Nakamura 2008), or in phonological markedness (Holden 1976; Itô and Mester 1999, 2001). Yet variability exists even among different words containing the same sound. For example, Hebrew does not have the semi-consonant /w/. While this sound gets adapted to /v/ in the Arabic loanword wadi ('valley'), it is retained in other words borrowed from Arabic, such as the interjection walla. This type of variability poses difficulty for phonological and phonetic accounts, especially when it occurs in phonologically similar environments, as in the example above.

One factor that accounts for some intra-feature variability is frequency. In general, frequency influences the way words are produced. The production of frequent words is often reduced, and with time, this can lead to their shortening (Zipf 1929). Frequency has also been shown to influence the 
likelihood that irregular forms, such as the irregular past-tense in English, will be maintained (Stemberger and MacWhinney 1986). In the realm of loanword adaptation, while the findings regarding the relationship between frequency and morphosyntactic integration are mixed (Poplack and Dion 2012; Poplack and Sankoff 1984), phonological adaptation does increase with loanword frequency (Friesner 2009; Poplack and Sankoff 1984; Poplack, Sankoff and Miller 1988). The effect of frequency is argued to be due to the tendency to integrate words more, the more they are used, and thus parallels the attested correlation between level of integration and time passed since the word's borrowing.

Additionally, even though the topic of variation in pronunciation has not received a lot of attention in research on loanword sound adaptation (but see, for instance, Holden 1976; Kang 2003; Paradis and LaCharité 1997), previous research has shown that pronunciation of a segment might differ even across native words. Psycholinguistic accounts have mostly focused on the influence of frequency, neighborhood density and similar factors on perception, and consequently production, by leading speakers to implicitly accommodate their speech to the listener (e.g. Wright 2004) or by influencing the speakers' own lexical access (Baese-Berk and Goldrick 2009). Sociolinguistic research that examined variation across words mostly revolved around the debate regarding lexical diffusion - whether sound change progresses simultaneously across the language's entire lexicon or whether it spreads gradually from one word to another (Labov 1981; Phillips 2006). Research on lexical diffusion has traditionally assumed that, eventually, all words would catch up and be pronounced using the same variant. Within the framework of exemplar-based phonology, though, stable lexically-based variation in pronunciation has been recognized and analyzed as such (e.g. Pierrehumbert 2002). We suggest that social factors could lead to systematic and not temporary differences between the pronunciation of different words. Additionally, the social factors whose effects we examine in this paper have not been examined before. Specifically, we will look at factors related to bilingualism and at the prestige of the donor language in the loanword's semantic domain.

\section{Bilingualism and sound adaptation}

As loanwords are borrowed from other languages, the role of bilingualism in borrowing and sound adaptation has often been raised. Bilinguals are typically assumed to be the agents of borrowing, the ones who use loanwords regularly and thus introduce them to the speech community, yet few studies have examined that empirically. Interestingly, one study that directly compared patterns of borrowing among speakers of different levels of proficiency in the second language found that while the overall rate of loanwords use does not differ with proficiency, the type of loanwords that are used does. Speakers with lower proficiency use mostly old loanwords while speakers with higher L2 
proficiency use newer loanwords and nonce loanwords, that is, foreign words that are not shared and used by the entire speech community and whose use is more idiosyncratic (Poplack, Sankoff and Miller 1988).

Bilingualism has also been suggested to be implicated in the process of sound adaptation. Haugen (1950) proposed that the degree to which loanwords go through sound adaptation depends on speakers' level of bilingualism. Late bilinguals have difficulties correctly pronouncing sounds in their second language if those sounds do not exist in their first language (e.g. Flege 1987). Furthermore, they have difficulty even perceiving phonological distinctions that are not used in their native language (for a review, see Sebastián-Gallés and Bosch 2005). Importantly, the influence of the native language on perception of sounds in other languages can influence patterns of loanword adaptation (e.g. De Jong and Cho 2012; Peperkamp, Vendelin and Nakamura 2008). Therefore, to the extent that difficulty in producing and perceiving nonnative sounds prevents speakers from producing accurate renditions of loanwords, the rate of sound adaptation should decrease with increased fluency in the donor language. Some studies have indeed found greater retention of foreign sounds in loanwords among speakers with higher education (Eklund and Lindström 2001) or higher proficiency in the donor language (Friesner 2009; Poplack, Sankoff and Miller 1988).

Level of bilingualism might also influence sound adaptation in loanwords at the community level, by influencing local norms and common practice. Poplack et al. (1988) compared sound adaptation in areas where the residents interact frequently with speakers of the donor language and areas where such interaction is rare. Neighborhood bilingualism played a role, with greater bilingualism reducing the rate of sound adaptation. Additionally, the effect of neighborhood bilingualism was stronger than the effect of individual proficiency. The same results were obtained in the study reported in San Giacomo and Peperkamp (2008) and San Giacomo (2009). In contrast, Friesner (2009) examined the role of neighborhood bilingualism on the rate of sound adaptation using loanwords from a variety of donor languages as well as neighborhoods with a varied composition of bilingual speakers. In this case, potentially due to the difference in the relation between the source of the loanword and the languages the area residents encounter, neighborhood bilingualism was less predictive of adaptation rate than individual bilingualism, and even when it surfaced, its influence was in the opposite direction; that is, adaptation rates were lower in the less bilingual neighborhoods.

Another aspect of bilingualism that is yet to be explored in relation to loanword adaptation is the role of interlocutors' bilingualism. The level of bilingualism of one's interlocutors, just like the neighborhood level of bilingualism, could influence the norms of the interaction. Moreover, interlocutors adapt their speech to one another in terms of lexical choice, pitch, speech rate and so on (Giles, Coupland and Coupland 1991). At the 
segmental level, such accommodation has been found both in non-interactive tasks at the lab (e.g. Babel 2012; Goldinger 1998), and in interactive situations in the real world (e.g. Coupland 1980; Pardo et al. 2012). For example, recordings of phone conversations of a travel agent in the U.K. have shown that her productions of regional varieties converged to the production of her interlocutors (Coupland 1980). Interestingly, repeated accommodation can lead to long-term influence (cf. Auer, Hinskens and Kerswill 2005). Thus, previously-unacquainted college roommates have been found to show moderate convergence in their pronunciations at the end of a semester of living together, and this convergence depended on the quality of their relationship (Pardo et al. 2012). This type of accommodation has indeed been linked to affiliative factors such as liking and attitude towards each other (Babel 2010, 2012; Bourhis and Giles 1977; Chartrand and Bargh 1999; Gregory, Dagan and Webster 1997; Pardo et al. 2012), as well as to interlocutors' relative prestige (Gregory and Webster 1996) and to speakers' desire for social affiliation (Natale 1975; Putman and Street 1984).

Speakers also adapt their speech to the linguistic level of their interlocutors, presumably to facilitate communication, as is evident in speech to foreign speakers (e.g. Uther, Knoll and Burnham 2007). Therefore, when faced with an interlocutor with a low level of bilingualism who cannot produce or perceive foreign sounds faithfully, a highly bilingual speaker might accommodate by adapting these foreign sounds as well.

Bilingualism can therefore influence the rate of sound adaptation at different levels. At the individual level, it can influence the speaker's ability to perceive and produce the foreign sounds correctly; at the neighborhood level, it can influence the local norms and common practices; and at the interaction level, it might influence sound adaptation via accommodation to one's interlocutors. In this study, we will examine the role of all three levels of bilingualism. In addition, we will examine whether accommodation per se, independently of level of bilingualism, influences sound adaptation. That is, one's interlocutors might choose to adapt or retain a foreign sound for reasons other than their ability to perceive and produce it, which might likewise influence one's rate of adaptation.

\section{Domain prestige and sound adaptation}

One of the main incentives for borrowing words is the prestige of the donor culture (e.g. Field 2002; Hogan 2003; Weinreich 1953). That is, words are borrowed not (only) for lack of the term in the borrowing language but in order to express expertise, educational standing, modernity, economic success, cultural superiority and so on. Through the use of loanwords the speaker identifies herself with the donor culture and thus shares its prestige. Therefore, words are often borrowed even when the borrowing language already has a term that carries the same meaning as the loanword. Furthermore, even when 
a lexical gap exists, it can be filled by means other than borrowing, such as coinage of new terms; thus, borrowing is rarely out of pure necessity. It is therefore unsurprising that borrowing is mostly from the language of the dominant community to the language of the politically, economically or culturally subordinate community (e.g. Hogan 2003; T'Sou 2001). Just as the likelihood of borrowing is guided by prestige, so might be the likelihood of retention of foreign sounds in loanwords; indeed, pronouncing a loanword with its foreign sounds intact could indicate affiliation with the donor culture even more strongly.

Prestige, of course, is rarely all encompassing. It is usually attached to specific domains, and the trends in borrowing reflect that. T'Sou's (2001) description of loan trends between English and Chinese demonstrates this fact: while in most fields the flow of words was from English to Chinese, in cuisine, it was English which borrowed Chinese terms along with the dishes which gained much popularity in the North American continent.

Yet words are borrowed at one point in time, and with time, the donor language may lose its prestige in that domain. Moreover, words might occasionally be borrowed despite minimal or non-existent differences in prestige, but because of the prevalence of bilingual speakers, requirements to use the foreign language in certain contexts, pressure from the majority language, or other contextual factors. Therefore, it might be the case that the degree to which speakers maintain the foreign sound depends on the current prestige of the donor culture, such that the more prestige the donor culture has in that domain, the less likely speakers will be to adapt the foreign sounds in that domain. One such suggestion for semantic conditioning in pronunciation has been put forward by Yaeger-Dror (1996). She proposed that a word's semantic network can influence the rate at which it would undergo a change, when there is a language change in progress. Specifically, she suggested that many of the words whose pronunciation did not manifest the ongoing sound change referred to older times (older family members, World War I, church), and this specific old-times semantic meaning is the reason their pronunciation was also as it was in the 'old days'. Unfortunately, this was a post-hoc hypothesis that was not tested empirically.

Abd-el Jawad and Suleiman (1990) proposed that some of the synchronic variability in pronunciation in spoken Arabic in Jordan is lexically conditioned. In particular, they argued that this variability depends on whether the word is borrowed from Standard Arabic and is therefore associated with the literary, formal and educated domain, whether it is shared by Colloquial and Standard Arabic, or, rather, whether it is specific to Colloquial Arabic and is associated with the domestic domain. Unfortunately, the confounding of semantic domain and etymological source and other technical and statistical issues in the paper hinder the ability to draw clear conclusions from the data about role of a word's domain. 
In this study, we propose that a word's semantic domain can influence the rate of sound adaptation. As we will show below, our study was conducted in a community in which two languages hold complementary prestige. ${ }^{2}$ This allowed us to examine whether the current prestige of the donor culture in a domain decreases the likelihood of sound adaptation.

\section{Language contact and prestige in Mexicano}

The data for the present study were collected in Tagcotepec, a Nahuatl village in central Mexico, where the main language of communication is Mexicano. Mexicano is an Uto-Aztecan language, and one of the most commonly spoken languages in Mexico. It has approximately 1.5 million speakers. An important source on the sociolinguistic situation regarding language use and attitudes towards Mexicano and Spanish is Hill and Hill (1986), who did extensive field work in a region characterized by a similar sociolinguistic situation. They discuss the extensive rate of borrowing from Spanish into Mexicano, and describe it as encompassing all domains and including all parts of speech. Still, they note that both the rate of use of loanwords and the rate of code-switches into Spanish is particularly high in the domains of religion, government, law and commerce - the areas where Spanish culture exerted the strongest influence, and therefore carries the highest prestige.

In the past, knowledge of Spanish was required for certain positions and for access to certain services. It therefore conferred both material and symbolic advantages. In recent times, however, with The General Law of Linguistic Rights of Indigenous People that recognizes the indigenous languages as national languages as well as residents' rights to use their local language and receive education and health services in it, Mexicano has (re-)gained prestige (Avilés 2009). The language attitudes in the area have shifted towards viewing Mexicano and Spanish as languages that serve complementary functions (Hill and Hill 1986; for Tagcotepec, see San Giacomo 2003). ${ }^{3}$ While Spanish is still associated with domains such as technology, education, religion, government and commerce, and its use is even required for commercial activities, in education and for receiving certain governmental services, Mexicano is associated with the social and local domains, and indicates solidarity and community membership.

Hill and Hill (1986) describe how both the rate of loanword use and frequency of switching into Spanish increases when speakers talk about law or government-related issues. They also found that speakers switch to Spanish in order to invoke religious expressions. In contrast, greetings are said solely in Mexicano, and in drinking contexts Mexicano dominates. Similar findings are reported with respect to Tagcotepec in San Giacomo (2003). In general, Mexicano is associated with respect, whereas Spanish is considered as the outside language, as distant, less trustworthy and more aggressive. One type of interaction that nicely exemplifies the complementary functions of the two 
languages is negotiations in the market: according to Hill and Hill, even though both buyer and vendor know Mexicano, the early stages of negotiation, where bargaining is more aggressive, is done in Spanish, since that is the language of commerce and distant matter-of-factness; yet when the speakers are about to close the deal, they switch to Mexicano to express solidarity. ${ }^{4}$ The emerging prestige of Mexicano is also evidenced in the growing interest among residents of villages where the use of Mexicano has declined to relearn the language, because they feel that Mexicano is required for exhibiting membership in their community.

To sum up, the current situation in some Mexicano-speaking areas, and particularly in the studied village, is of complementary prestige of Spanish and Mexicano, where both languages are perceived positively but for different reasons, and use of each is aimed at serving different functions. Use of Spanish, in the form of either increased use of Spanish loanwords in Mexicano or a complete language-switch into Spanish, serves to add education, commerce, and religion-related prestige while simultaneously projecting distance. In contrast, use of Mexicano projects solidarity, respect and community membership. We will examine whether these complementary patterns of prestige and language use are also reflected in rate of sound adaptation in Spanish loanwords.

\section{DATA AND METHODS}

The data for this study were collected by the second author in Tagcotepec, a Nahuatl village of approximately 500 inhabitants in the Sierra Norte de Puebla, Mexico (San Giacomo 2009). Previous analyses of this dataset are reported in San Giacomo and Peperkamp (2008) and San Giacomo (2009). Unlike many neighboring villages, Mexicano remains the main language used for communication in this village, and it is the native language of almost all residents. It is not currently endangered. The combination of high prevalence of Spanish loanwords yet dominance in Mexicano in this village makes it optimal for conducting a study on loanwords, whose prevalence in running speech in other speech communities is often quite low. The language attitudes in the area also present a unique opportunity to examine the role of language prestige. Additionally, we examined the roles of individual bilingualism, neighborhood bilingualism, and interlocutors' bilingualism, as well as word frequency and accommodation to one's interlocutors irrespective of their level of bilingualism in sound adaptation. Note that the role of individual bilingualism, neighborhood bilingualism, and frequency had already been analyzed for this dataset, albeit with different statistical methods (San Giacomo and Peperkamp 2008; San Giacomo 2009).

The dominant language of the village, Mexicano, is an Uto-Aztecan polysynthetic language, which is typologically unrelated to Spanish. The two languages, therefore, do not share lexical items, except for those that have 
Table 1: The vowel inventories of Mexicano and Spanish

\begin{tabular}{|c|c|c|c|c|c|c|}
\hline & \multicolumn{2}{|c|}{ Front } & \multicolumn{2}{|c|}{ Central } & \multicolumn{2}{|c|}{ Back } \\
\hline & Short & Long & Short & Long & Short & Long \\
\hline \multicolumn{7}{|l|}{ Mexicano: } \\
\hline Closed & i & i: & - & - & $(\mathrm{u})^{*}$ & $(\mathrm{u}:)^{*}$ \\
\hline Intermediate & $\mathrm{e}$ & e: & - & - & o & o: \\
\hline Open & - & - & a & a: & - & - \\
\hline \multicolumn{7}{|l|}{ Spanish: } \\
\hline Closed & i & - & - & - & $\mathrm{u}$ & - \\
\hline Intermediate & e & - & - & - & o & - \\
\hline Open & - & - & a & - & - & - \\
\hline
\end{tabular}

*In Mexicano, [u] and [u:] are context-free allophones of /o/ and /o:/, respectively.

been borrowed from one into the other. Tables 1 and 2 present the vowel and consonant inventories, respectively, of Mexicano and Spanish. As can be seen, Mexicano uses the same vowels as Spanish (with the proviso that $[\mathrm{u}]$ is a context-free allophone of [o]), and in addition it has a vowel length contrast. However, Mexicano lacks eight of the Spanish consonants, i.e. /b/, /d/, /g/, /f/, $/ \mathrm{x} /, / \mathrm{n} /, / \mathrm{r} /$ and $/ \mathrm{r} /$. Additionally, consonant clusters are disallowed in Mexicano but licensed in Spanish. Our study therefore focused on the pronunciation of these consonants as well as of consonant clusters in Spanish source words (for a more detailed comparison of the phonological systems of Spanish and Mexicano, see San Giacomo 2009).

Table 2: The consonant inventories of Mexicano and Spanish. Spanish consonants that do not exist in Mexicano are written in bold

\begin{tabular}{|c|c|c|c|c|c|c|c|}
\hline & Labial & Labio-dental & Dental & Alveolar & Palatal & Velar & Glottal \\
\hline \multicolumn{8}{|c|}{ Mexicano: } \\
\hline stop & $\mathrm{p}$ & - & - & $\mathrm{t}$ & - & $\mathrm{k} / \mathrm{k}^{\mathrm{W}}$ & (?) \\
\hline fricative & - & - & - & $\mathrm{s}$ & $\int$ & - & (h) \\
\hline affricate & - & - & - & ts & $\mathrm{t} \int$ & - & - \\
\hline spirant & $w$ & - & - & l & $\mathrm{j}$ & - & - \\
\hline nasal & $\mathrm{m}$ & - & - & $\mathrm{n}$ & - & - & - \\
\hline \multicolumn{8}{|l|}{ Spanish: } \\
\hline stop & $\mathrm{p}, \mathbf{b}$ & - & $\mathrm{t}, \mathbf{d}$ & - & - & $\mathrm{k}, \mathbf{g}$ & - \\
\hline fricative & - & f & - & $\mathrm{s}$ & - & $\mathbf{x}$ & - \\
\hline affricate & - & - & - & - & $\mathrm{t} \int$ & - & - \\
\hline spirant & w & - & - & l & $\mathrm{j}$ & - & - \\
\hline nasal & $\mathrm{m}$ & - & - & $\mathrm{n}$ & $\mathrm{n}$ & - & - \\
\hline flap & - & - & - & $r$ & - & - & - \\
\hline tril & - & - & - & $\mathbf{r}$ & - & - & - \\
\hline
\end{tabular}




\section{Method}

In this study, we used a lenient definition of loanwords and examined the production of foreign consonants and of consonant clusters in all Spanish words that were produced during the task, regardless of whether these were loanwords that are already attested in dictionaries, relatively new loanwords, or even words that might only be used idiosyncratically by specific individuals (nonce-borrowings). In previous work, different methodologies have been used to elicit productions of loanwords, including picture denomination, free conversation, and sociolinguistic interviews. Each of these methods, however, presents disadvantages; for instance, speakers might change their pronunciation when they interact with someone from outside their speech community or when they produce loanwords in isolation after being prompted explicitly, whereas they might produce relatively few loanwords in free conversation. We therefore used for this study a new method developed by San Giacomo (2011), which allows for the recording of spontaneous productions of a large number of loanwords during conversations with multiple speakers and without interference from the researcher. Specifically, the second author of this article, who knows basic Mexicano and is highly familiar with the area of this village, assembled a set of 270 pictures depicting objects that speakers in that area often refer to using Spanish loanwords. These included both common objects that are in common use in the village, such as a tortilla, and things that the speakers do not encounter in the area, such as a giraffe. These pictures were then presented to groups of two to four speakers, who were asked to talk about them. They were presented both as individual cards and in one large collage which additionally included 30 more pictures that depicted some of the same objects, in order to increase the rate at which they are referenced. The speakers all knew one another and interlocutors in the same session were family members, friends or neighbors. Each session was led by one of three village residents. To the extent that they were naïve to the specific hypotheses, they also participated in the sessions they led. The second author was present but did not participate in any of the sessions. It was explained to the participants that she was there to improve her knowledge of Mexicano; she thus observed the sessions from a short distance. Most sessions were held at the home of one or more participants. While the speakers were prompted with pictures of the target objects, their speech included many additional loanwords. In all, 44 sessions were conducted, for a total of 69 speakers and approximately 25 hours of recorded spontaneous speech. $^{5}$

Below are two examples of sentences with loanwords (written in bold) that participants uttered when looking at the pictures. The first sentence presents a case in which the foreign segment $/ \mathrm{n} /$ in the loanword (niño) is adapted: 
(1) Phonetic transcription:

Orthographic transcription:

Close translation:

Free translation: nitak se níinjo katoni? (Spanish pronunciation: /níno/)

ni-ita-k se niño ka-tóni?

1sg-SEE-past one child-ligature-BREAK

I saw a child who cuts (something)

The second example illustrates cases where the foreign segments (e.g. $\mathrm{r}$ or consonant clusters) were maintained:

(2) Phonetic transcription: Orthographic transcription: Close translation:

Free translation: maéest a niták le óohtok maestra ni-ita-k Ø-leeroh-t-o-k teacher 1sg-SEE-past 3rs-READ- ligature-Positional Verb BE- Present

I saw the teacher who was reading

\section{Coding}

Foreign segments. All loanwords that occurred in the sessions, whether referring to the depicted objects or not, were phonetically transcribed by the second author, a native Spanish speaker who also speaks basic Mexicano. She identified all consonants in the Spanish source words that are foreign to Mexicano and coded whether speakers pronounced them faithfully or adapted them by substituting them with Mexicano consonants or deleting them altogether. Cases in which the speaker substituted the consonant with another consonant that is foreign to Mexicano were excluded (146 cases, 1.5\%). The coder also coded whether consonant clusters were simplified or not. The present analysis considered only those clusters composed of consonants that exist in Mexicano, thus excluding clusters in which one or both consonants do not occur in the language. This was done to avoid counting the same consonant token twice, especially since cluster simplification and adaptation of one of the cluster's consonants are not independent of one another.

Frequency. There are no frequency statistics on words in Mexicano. Therefore, the second author estimated the frequency of all words based on her knowledge of the language and of the use of loanwords in the village. Three levels of frequency were used: High, Medium and Low.

Individual bilingualism. Participants' level of bilingualism was initially classified by the second author and in consultation with a local assistant into one of four levels:

- level $1=$ monolingual Mexicano speakers who neither speak nor comprehend Spanish;

- level 2 = Mexicano speakers who do not speak Spanish but can understand it; 
- level 3 = Mexicano speakers who speak some Spanish, but not as well as they can understand it;

- level 4 = Mexicano speakers who both speak and understand Spanish.

Since the distribution was highly skewed, with the majority of the speakers falling into level 4 , the first three levels were collapsed into one level (less bilingual), and compared with the more bilingual speakers of level 4 . We did not use an objective measure of proficiency, because some of the participants were illiterate, and because there are no Spanish proficiency tests developed for Mexicano speakers that take into account their context of learning and consequent learning trajectory.

Neighborhood bilingualism. Tagcotepec is composed of two sections separated by a river. The section of the village that is on one river bank is easily accessed by road. All public buildings - the church, the school, the municipality and the phone booth - are concentrated in that section of the village, and therefore most Spanish activities take place there as well. This is the village section that also receives the most contact with the Spanish language and its speakers. The other section of the village, on the opposite bank of the river, stretches into the mountains. It is less accessible and more isolated. Many services and infrastructural developments, such as electricity and telephone lines, have reached it later, and contact with Spanish and its speakers is lower. We coded for each speaker whether they live in the accessible or isolated section of the village.

Interlocutors' bilingualism. Interlocutors' bilingualism was coded at the session level. If at least 75 percent of the participants in the session were of bilingualism level 4 , and the rest were classified at level 3, interlocutors' bilingualism was classified as high. Otherwise, it was classified as low. Note that in this case the use of a subjective measure based on the impression of members of the village is superior to use of an objective measure, as we hypothesize that speakers accommodate to interlocutors according to their expectations regarding their interlocutors' proficiency rather than according to interlocutors' objective proficiency.

Language prestige. All words were classified as belonging to one of the Spanish or Mexicano domains of prestige or as Other. For Spanish prestige, we coded whether words belonged to the domains of high technology (e.g. television), medium technology (e.g. clock), low technology (e.g. umbrella), education (e.g. teacher), commerce (e.g. money), government (e.g. president), or religion (e.g. priest). For Mexicano prestige, we coded whether words belonged to the social (e.g. family) or local (e.g. tortilla) domains. The remaining words (e.g. giraffe) were coded as Other. 
Accommodation. The analysis of accommodation was conducted separately, because it included only tokens of foreign segments whose latest prior appearance was in the speech of a different interlocutor. For each of these tokens we coded whether it was adapted the previous time it was uttered. We further coded whether this previous appearance of this segment was within the same word as the current token or in a different one.

\section{Sample characteristics}

Thirty men and 39 women participated. Their ages ranged from 12-85 years $\left(\mathrm{M}=37\right.$ years, $\mathrm{SD}=18$ years). ${ }^{6}$ Twenty participants were classified as being less bilingual, and 49 as being more bilingual. Sixteen of the sessions were classified as consisting of less proficient interlocutors, and 28 sessions were classified as consisting of proficient interlocutors.

Over the course of all sessions, 771 different loanwords whose Spanish source includes foreign segments were produced, yielding 4,616 word tokens, each containing between one and five foreign segments. Overall, there were 8,023 instances of foreign segments. Among the 771 loanwords, 226 were of low frequency, 121 were of medium frequency and 424 were of high frequency. The majority of the words (547) did not belong to either Spanish or Mexicano-prestige domains. Among the remaining ones, 130 belonged to Spanish-prestige domains and 94 to Mexicano-prestige domains.

The 69 speakers did not contribute equally to the data set. The number of target segments that speakers produced ranged from 3 to 1,195 (M=118.6, $\mathrm{SD}=187.4$ ). In fact, because the local residents who directed the sessions participated in many of them, the productions of two of them account for 28 percent of the data. Similarly, not all words were equally frequent in our data set. Words appeared between one and 55 times $(M=6, S D=16)$, with 416 of them appearing only once. ${ }^{7}$

The paper focuses on sound adaptation rate, regardless of how the sound was adapted, yet it is interesting to note that there was great crossword and cross-speaker variability in the way that the foreign segments had been adapted. Each of the foreign segments had been adapted in multiple manners, sometimes by the same speaker. Similarly, many words had been adapted in multiple different ways, sometimes even by the same speaker. For example, the trill in the Spanish word reloj (clock) had been adapted to $/ \mathrm{k} /, / \mathrm{p} /$, $/ \mathrm{h} /, / \mathrm{t} /, / \mathrm{t} /$, as well as been deleted, on different occasions (see the Appendix for a comprehensive list of all types of adaptations).

\section{Results}

In general, the rate of adaptation was low and stood at 15 percent, with individual speakers adapting between zero percent and 47 percent of foreign segments (Figure 1). 


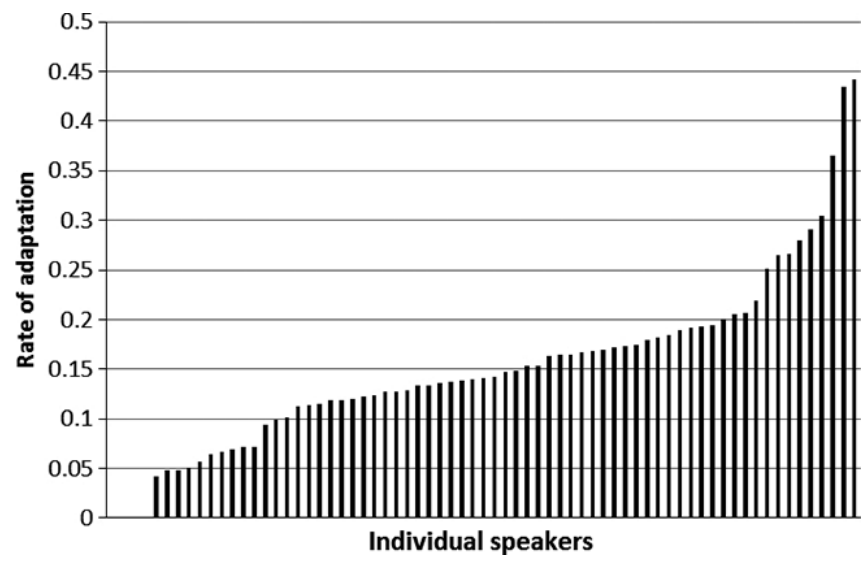

Figure 1: Speakers' individual rate of sound adaptation

Segments differed in their likelihood of being adapted, ranging from 7.9 percent for $/ \mathrm{b} /$ to 40 percent for $/ \mathrm{r} / .^{8}$ In order to test whether sound adaptation depends on bilingualism at different levels, on language prestige and on word frequency, we conducted a mixed model analysis with Speakers and Words as random variables, and Individual Bilingualism, Neighborhood Bilingualism, Interlocutors' Bilingualism, Language Prestige, and Frequency as fixed factors. ${ }^{9,10}$ Our model included intercepts for the random variables as well as a slope for Language Prestige for the Speaker variable, and slopes for Neighborhood Bilingualism and Interlocutors' Bilingualism for the Word variable. $^{11}$

The analysis revealed an effect of Language Prestige, such that foreign segments in words that belong to Spanish-prestige domains were less likely to be adapted ( $\beta=-0.47, p<0.04$; see Table 3 for the full table of results). Foreign segments in words that belong to Mexicano-prestige domains and segments in words that do not belong to either type of domain did not differ in their probability of being adapted, although the former were adapted a bit more often numerically (Figure 2).

Figure 3 shows the likelihood of sound adaptation by domain (excluding Other). As can be seen, the likelihood of adaptation in the Spanish-prestige domains of commerce, education, government and hi-tech is very low and, importantly, lower than the rate of adaptation in the Mexicano-prestige local and social domains. Furthermore, an examination of the rate of adaptation in the domain of technology even shows that, numerically, the rate of adaptation drops the more sophisticated (and, to a degree, less common), the technology is, and therefore, the more prestigious it is. One caveat is that words describing high technology might have entered the language on average more recently than words of medium and low technology, and it has been shown that words become more integrated into the language with time (Friesner 2009; Poplack 
Table 3: Full table of results for likelihood of sound adaptation by language prestige, word frequency and different levels of bilingualism.

\begin{tabular}{lrrrc}
\hline & Estimate $(\beta)$ & SE & z & p \\
\hline Intercept & -2.47126 & 0.18920 & -13.062 & $<2 \mathrm{e}-16^{* *}$ \\
$\begin{array}{l}\text { Language prestige } \\
\quad \text { Mexicano) }\end{array}$ & 0.08573 & 0.26765 & 0.320 & 0.74874 \\
$\begin{array}{l}\text { Language prestige } \\
\quad \text { Spanish) }\end{array}$ & -0.46645 & 0.22664 & -2.058 & $0.03958^{*}$ \\
$\quad \begin{array}{l}\text { Neighborhood } \\
\text { bilingualism (less) }\end{array}$ & 0.79604 & 0.15159 & 5.251 & $1.51 \mathrm{e}-07^{* *}$ \\
$\begin{array}{l}\text { Interlocutors' bilingualism } \\
\quad \text { proficient) }\end{array}$ & -0.43116 & 0.13489 & -3.197 & $0.00139^{* *}$ \\
$\quad \begin{array}{l}\text { Individual bilingualism } \\
\text { Frequency }\end{array}$ & -0.01043 & 0.18633 & 0.056 & 0.95537 \\
\hline
\end{tabular}

*Significant at $\mathrm{p}<0.05 ;{ }^{* *}$ Significant at $\mathrm{p}<0.01$.

and Sankoff 1984; Poplack et al. 1988). Unfortunately, we do not have information regarding the date of borrowing for most words in our sample. At the same time, many of the high technology words in our sample are of objects that were invented a century ago or even earlier (e.g. bomb and truck), and many of the words of medium and low technology are of objects that were only invented or have reached the village in the last century, such as stapler (low) and bicycle (medium).

The domain of religion seems to stand out by exhibiting a relatively high rate of adaptation despite its classification as a Spanish-prestige domain. This might be due to the fact that words in that domain are likely to have been borrowed

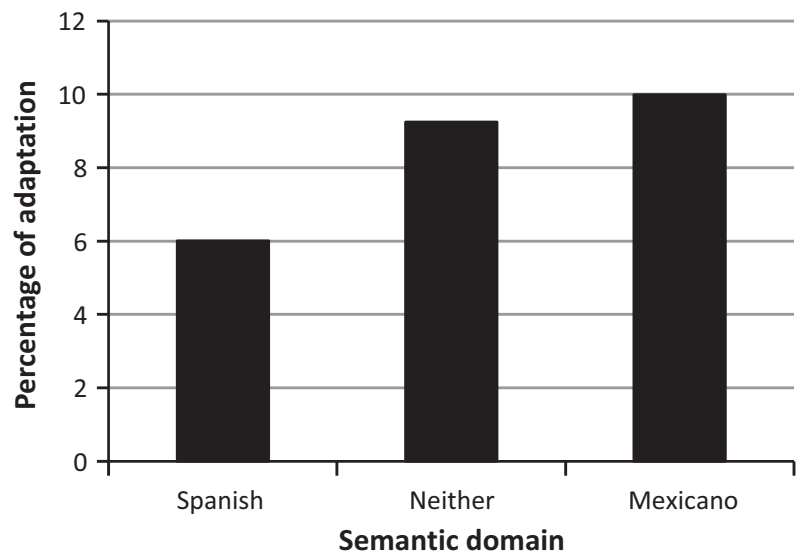

Figure 2: Percentage of sound adaptation by the prestige of the word's semantic domain 


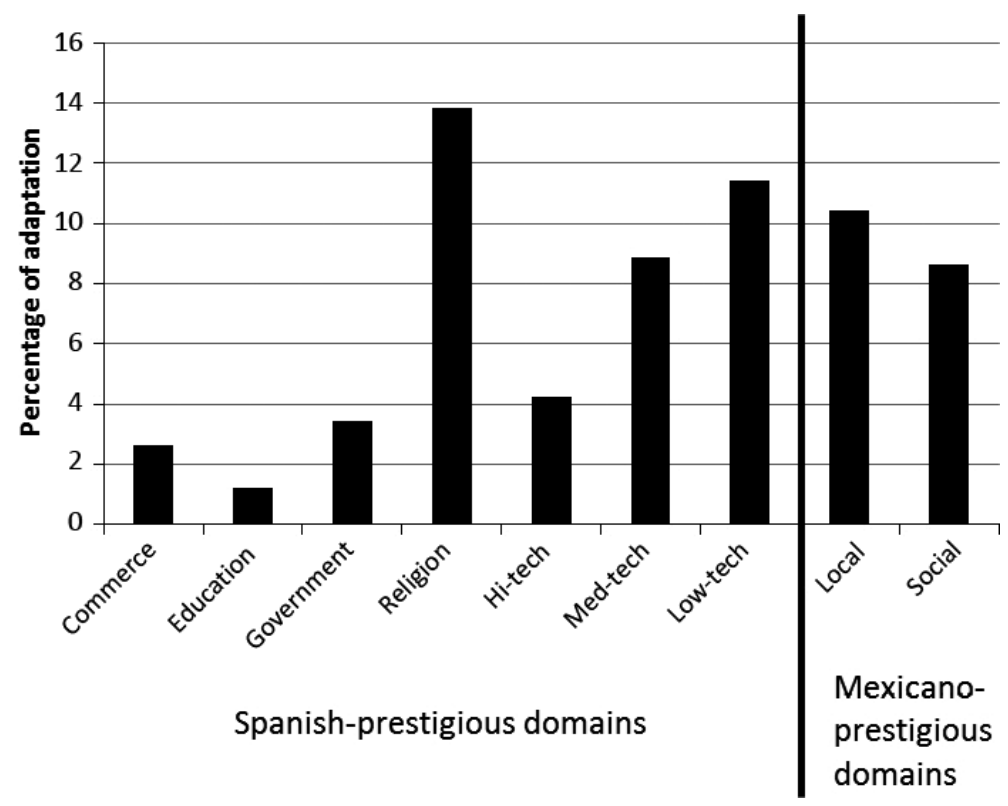

Figure 3: Percentage of sound adaptation by semantic domain

at an earlier period of time. Alternatively, the domain of religion might show a different pattern because the religion itself was adopted already a few centuries ago, and is not perceived as Spanish, especially since Christianity in Mexico differs from Christianity in Western Europe (Griffiths and Cervantes 1999), and religious observance tends to be higher in rural Mexicano-speaking communities than it is in urban Spanish-speaking communities. Additionally, religion is more personal, and Mexicano signifies intimacy and closeness whereas Spanish projects distance.

Interlocutors' Bilingualism proved to predict rate of sound adaptation as well, such that speakers adapted less if their interlocutors were more proficient in Spanish than if they were not $(\beta=-0.43, p<0.01$; Figure 4$)$. One caveat is that the coding of Interlocutors' Bilingualism is based on the subjective coding of Individuals' Bilingualism. The latter was coded according to the impression of the second author and the local assistants rather than according to an objective measure. That said, speakers' accommodation is also driven by their impression of the level of bilingualism of their interlocutors rather than necessarily the actual level of proficiency. Therefore, a measure based on impression from manifested behavior is likely a relatively good proxy for capturing the factor influencing speakers' accommodation.

The analysis also replicated the effect of Neighborhood Bilingualism reported in San Giacomo and Peperkamp (2008) and San Giacomo (2009). Segments produced by speakers who live on the more isolated bank of the river were 


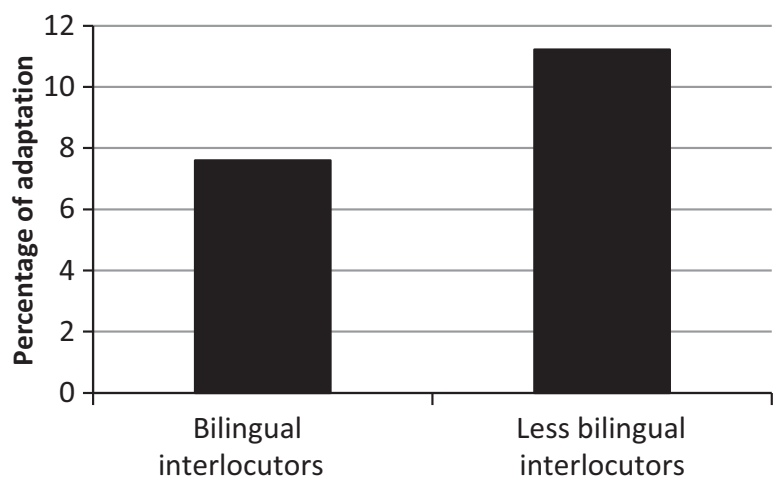

Figure 4: Percentage of sound adaptation by interlocutors' level of bilingualism

more likely to adapt foreign segments $(\beta=0.8, \mathrm{p}<0.001)$. In contrast, individual level of bilingualism did not predict sound adaptation.

Word frequency, however, did not predict the likelihood of sound adaptation. Since our measures of individual bilingualism and word frequency were relatively coarse as well as subjective, it is unclear whether they play no role in sound adaptation or whether our measures were not sensitive enough to capture their role.

We next examined whether speakers accommodated to each other, modifying their rate of sound adaptation according to whether their interlocutors adapted the foreign sound. We also examined whether speakers were more likely to adapt if the segment they produced was previously produced in the same word compared to a different word, since, in general, accommodation, at least in terms of structural priming, tends to be stronger when words are repeated (Branigan, Pickering and Cleland 2000). To test this, we ran an analysis only on cases where a target segment was previously produced by another speaker in the interaction in either the same or a different loanword $(\mathrm{N}=3113)$. Our model included Speakers and Words as random variables, and Previous Production and Word Repetition as fixed factors. Only the intercepts of the random variables were included. The analysis revealed that speakers are more likely to adapt a segment if the previous speaker adapted it as well $(\beta=1.31, p<0.01$; Figure 5$)$ and regardless of whether it appeared in the same word or a different one (Table 4 shows the full table of results).

\section{DISCUSSION}

Loanword sound adaptation varies a lot both across and within words. Linguistic theories cannot explain such variability, especially when a specific segment borrowed from one specific language into another one in similar 


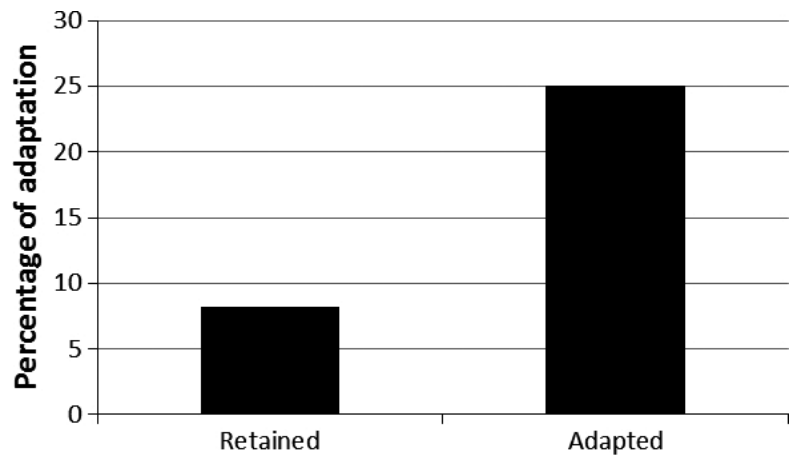

Figure 5: Percentage of sound adaptation as a function of whether the previous interlocutor adapted the sound

Table 4: Full table of results for accommodation

\begin{tabular}{lcccc}
\hline & Estimate $(\beta)$ & $\mathrm{SE}$ & $\mathrm{z}$ & \multicolumn{1}{c}{$\mathbf{p}$} \\
\hline Intercept & -2.4100 & 0.1304 & -18.475 & $<2 \mathrm{e}-16$ \\
Interlocutor's adaptation & 1.3130 & 0.1225 & 10.720 & $<2 \mathrm{e}-16^{* *}$ \\
Same word & 0.1288 & 0.1285 & 1.002 & 0.316 \\
\hline
\end{tabular}

**Significant at $\mathrm{p}<0.01$.

linguistic context is sometimes adapted and other times retained in its original form. Some researchers have started examining the role of speaker-specific characteristics and social factors in accounting for this variation. Notably, Poplack et al. (1988) and San Giacomo (2009) have found that the neighborhood's level of bilingualism can influence level of sound adaptation (but see Friesner 2009). Our study further shows the extent to which loanword sound adaptation is socially conditioned and provides a possible explanation for the role of neighborhood bilingualism. Specifically, our study shows that whether or not foreign segments in loanwords are adapted depends on the social meaning the loanword carries and on speakers' current as well as frequent interlocutors.

By conducting a study in Tagcopetec, Mexico, an area where languages hold complementary prestige, we were able to show that social factors can also lead to systematic intra-speaker variation that is conditioned on the word's semantic domain. In particular, we showed that the likelihood of sound adaptation depends on whether or not the specific foreign segment occurs in a word that is associated with a domain in which the donor language is considered prestigious. When the donor culture is considered relatively prestigious in that domain, as is the case with Spanish loanwords in the domains of commerce, education, government, religion and technology, the 
likelihood that the foreign segments would be retained rises compared to when the prestige of the donor culture in that domain is relatively low, as is the case in the local and social domains.

This finding suggests that different types of words might follow different sound adaptation trajectories, such that words from Spanish-prestigious domains will not simply be adapted as time goes by but rather retain their foreign segments as long as Spanish holds prestige in these domains. Further research is needed to investigate this possibility. Indeed, since our study examined synchronic variation and did not include a longitudinal aspect, our results cannot exclude the possibility that sound adaptation starts with words in Mexicano-prestigious domains and then spreads to Spanish-prestigious domains. At the same time, languages abound with cases of loanwords whose pronunciation was never fully adapted, indicating that such a spreading scenario is not always appropriate. In fact, it is through retention of foreign sounds that borrowing leads to sound changes. Therefore, prestige might be one of the factors that determine whether foreign sounds remain unadapted and eventually enter the language.

While our study examined the role of domain prestige at the community level, individual attitudes towards the donor language and individual differences in the perceived importance of the domain could influence sound adaptation as well. Furthermore, it might be the case that the positivity of the context in which a loanword is used interacts with domain prestige in its influence on sound adaptation. In other words, a foreign sound in an education-related loanword might be retained when the speakers refer to a good education system or a positive aspect of it, but not when they complain about it. Additionally, social attitudes towards the donor language might influence not only whether a segment is adapted but also how. In our study, we evidenced great variability in the manner in which foreign sounds were adapted. For example, some of the speakers who adapted the / $/$ in the Spanish word tortilla adapted it to $/ \mathrm{J} /$ while others adapted it to $/ 3 /$. It might be the case that such variation is conditioned by social factors as well. Further research is required to examine these issues.

In this study we investigated for the first time the role of a speaker's current interlocutors on likelihood of sound adaptation. Our results indicate that if one's interlocutors adapt the foreign sound, the speaker would be inclined to do so as well. This extends previous research that shows that speakers adapt other aspects of their speech, such as speech rate or pitch, in convergence with their interlocutors' behavior (Giles et al. 1991). Our results also indicate that speakers adjust their likelihood of sound adaptation to their interlocutors' needs. Just as speakers adapt to language learners' needs by speaking more clearly (e.g. Uther et al. 2007), so they adapt to their interlocutors' level of bilingualism, adapting foreign sounds more frequently, the lower their interlocutors' level of bilingualism is. These findings are the first to explain some of the variability in whether or not sounds are adapted within speakers, 
even when they use the same word, only in different contexts. They therefore show the sensitivity of sound adaptation to contextual social conditions. Furthermore, the fact that we found both speakers' current interlocutors and speakers' neighborhood to play a role in sound adaptation suggests a mechanism by which speakers' social network can shape their patterns of sound adaptation. Our results show that speakers' productions are influenced by their interlocutors in the immediate interaction. It is possible that repeated interactions with less vs. more bilingual speakers, and thus repeated accommodation to their level of bilingualism leads to the emergence of different norms in more vs. less bilingual neighborhoods or to other higher level sociolects in areas where interactions are less governed by geographical proximity.

Some converging evidence for the results presented here comes from a recent experimental study that we ran and that replicated the findings reported here in a laboratory setting. Specifically, small groups of participants played a game revolving around a supposedly novel Italian product whose name starts with /dz/, which does not exist in French. We found that while playing the game, participants were more likely to retain the foreign segment when they had been told the product was a new ice-cream, for which Italy is renown, than when they had been told it was a new beer, for which Italy is not particularly known. Furthermore, interlocutors adapted to one another, and this adaptation led to the emergence of norms (Lev-Ari and Peperkamp 2014).

To conclude, the present paper extends research on variability in sound adaptation at the community level and introduces the study of variability in sound adaptation at the individual level. It shows that individuals vary in their pronunciation of loanwords from one context to another, and that this variability is socially conditioned. These results suggest that whether or not the sounds of one language will be introduced into a different language via loanwords could depend on social factors such as the prestige that the donor language holds and speakers' level of bilingualism and on interaction patterns.

\section{NOTES}

1. This research was funded by the Agence Nationale de la Recherche (ANR-10LABX-0087, ANR-10-IDEX-0001-02), and by Fondation Pierre-Gilles de Gennes.

2. Note that the term complementary prestige does not indicate that speakers' attitudes towards the two languages are equally positive. The term indicates that each language is of value in different domains, but whereas the speakers in the studied village see Mexicano positively, their attitude towards Spanish is ambivalent at best, as it is a language that was imposed on them, and threatened the maintenance of their own language. Note that complementary prestige is also different from diglossia. Speakers might view a language as prestigious in a domain even if they do not use the language 
when talking about that domain (for lack of sufficient proficiency, for example).

3. Note that this situation of language equilibrium is specific to the studied area. In other regions in Mexico, the prevalent situation is disglossic with the two languages competing with one another and trying to appropriate more fields of communication (e.g. Flores Farfán 1999; San Giacomo 2003, 2009; Vallverdú 1973).

4. While this example illustrates the attitude towards Spanish and Mexicano, it does not characterize interactions in the market in the specific studied village. The local market is a barter exchange market located in a neighboring village, where Mexicano is no longer spoken. Still, as all the traders are Mexicano speakers, all barter exchange is conducted in Mexicano, as is appropriate for an economic system that is indigenous and not associated with Spanish culture (San Giacomo 2003, 2009).

5. A more detailed description of the sample and of other aspects of the method can be found in San Giacomo and Peperkamp (2008) and San Giacomo (2009).

6. Twenty-one children below the age of 12 participated as well but were excluded from analysis, since they might have not yet fully acquired the social conditioning of loanword pronunciation.

7. We analyzed our data with a mixed model that included Speakers and Words as random variables. Such mixed models take into account the dependency of data points that belong to the same speaker or word, search for clusterings and model them. Therefore, they can deal with skewed data sets.

8. An alternative way for controlling for the effect of foreign segment is to include segment as a factor in the analysis. When we run the mixed model analysis with this factor and its interaction with Prestige, the results are the same as those reported in the analysis below that does not include the factor. The results of a mixed model, however, are not reported for the average data point across all levels of the other factors, but for the model at its baseline, which in our analysis, was when the segment is $/ r /$, the most frequent one. In order to be able to present the effects across all segments in one analysis, we present the results in a model that does not include segment as a factor.

9. An early analysis did not reveal a main effect of gender, and since we also did not predict gender effects we collapsed the responses by male and female speakers.

10. A different analysis that also included Number of Foreign Segments in a word as a variable revealed an effect of Number of Foreign Segments, such that a greater number of foreign segments in a word reduced the likelihood of each of them to be adapted $(\beta=-0.23, p<0.01)$. Other than that, all effects were the same in the model that includes this variable and in the model that does not. Since this variable does not bear relevance to our main hypotheses, we report in the main text the model that does not include it.

11. In this as well as later analyses in the paper, slope inclusion was decided by comparing, for each slope, a model containing the slope to a model without it using a Ratio Likelihood test (Baayen 2008: 275). We retained slopes that improve the model at least marginally $(\mathrm{p}<0.1)$. 


\section{REFERENCES}

Abd-el Jawad, Hassan R. S. and Saleh M. Suleiman. 1990. Lexical conditioning of phonological variation. Language Sciences 12: 291-330.

Auer, Peter, Frans Hinskens and Paul Kerswill (eds.). 2005. Dialect Change: Convergence and Divergence in European Languages. Cambridge, U.K.: Cambridge University Press.

Avilés, Karla. 2009. Retos y paradojas de la reivindicación nahua en Santa Catarina, Tepoztlán, Morelos. Unpublished Doctoral dissertation. Mexico: Centro de Investigaciones y Estudios Superiores en Antropología Social.

Baayen, R. H. 2008. Analyzing Linguistic Data. A Practical Introduction to Statistics Using R. Cambridge, U.K.: Cambridge University Press.

Babel, Molly. 2010. Dialect convergence and divergence in New Zealand English. Language in Society 39: 437-456.

Babel, Molly. 2012. Evidence for phonetic and social selectivity in spontaneous phonetic imitation. Journal of Phonetics 40: 177-189.

Baese-Berk, Melissa and Matthew Goldrick. 2009. Mechanisms of interaction in speech production. Language and Cognitive Processes 24: 527-554.

Boretzky, Norbert. 1991. Contact-induced sound change. Diachronica 8: 1-15.

Bourhis, Richard Y. and Howard Giles. 1977. The language of intergroup distinctiveness. In Howard Giles (ed.) Language, Ethnicity, and Intergroup Relations. London: Academic Press. 119-136.

Branigan, Holly P., Martin J. Pickering and Alexandra A. Cleland. 2000. Syntactic coordination in dialogue. Cognition 75: B13-B25.

Chartrand, Tanya L. and John A. Bargh. 1999. The chameleon effect: The perceptionbehavior link and social interaction. Journal of Personality and Social Psychology 76: 893-910.

Coupland, Nikolas. 1980. Style-shifting in a Cardiff work-setting. Language and Society 9: 1-12.

De Jong, Kenneth and Mi-Hui Cho. 2012. Loanword phonology and perceptual mapping: Comparing two corpora of Korean contact with English. Language 88: 341-368.

Eklund, Robert and A. Lindström. 2001. Xenophones: An investigation of phone set expansion in Swedish and implications for speech recognition and speech synthesis. Speech Communication 35: 81-102.

Field, Fredric W. 2002. Linguistic Borrowing in Bilingual Contexts. Philadelphia, Pennsylvania/ Amsterdam, The Netherlands: John Benjamins Publishing Company.

Flege, James Emil. 1987. The production of 'new' and 'similar' phones in a foreign language: Evidence for the effect of equivalence classification. Journal of Phonetics 15: 47-65.

Flores Farfán, A. J. 1999. Cuatreros somos y toindioma hablamos: Contactos y contactos y conflictos entre el náhuatl y el español en el sur de México. México: Centro de Investigaciones y Estudios Superiores en Antropología Social-Secretaría de Educación Pública-Consejo Nacional de Ciencia y Tecnología.

Friesner, Michael L. 2009. The social and linguistic predictors of the outcomes of borrowing in the speech community of Montreal. Unpublished Doctoral dissertation. Philadelphia, Pennsylvania: University of Pennsylvania.

Giles, Howard, Nicholas Coupland and Justine Coupland. 1991. Accommodation theory: Communication, context, and consequence. In Howard Giles, Justine Coupland and Nikolas Coupland (eds.) Contexts of Accommodation: Developments in Applied Sociolinguistics. Cambridge, U.K.: Cambridge University Press. 1-68. 
Goldinger, Stephen D. 1998. Echoes of echoes? An episodic theory of lexical access. Psychological Review 105: 251-279.

Gregory, Stanford W. Jr., Kelly Dagan and Stephen Webster. 1997. Evaluating the relation of vocal accommodation in conversation partners' fundamental frequencies to perceptions of communication quality. Journal of Nonverbal Behavior 21: 23-43.

Gregory, Stanford W. Jr. and Stephen Webster. 1996. A nonverbal signal in voices of interview partners effectively predicts communication accommodation and social status perceptions. Journal of Personality and Social Psychology 70: 1231-1240.

Griffiths, Nicholas and Fernando Cervantes (eds.). 1999. Spiritual Encounters: Interactions between Christianity and Native Religions in Colonial America. Lincoln, Nebraska: University of Nebraska Press.

Haugen, Einar. 1950. The analysis of linguistic borrowing. Language 26: 210-231.

Hill, Jane H. and Kenneth C. Hill. 1986. Speaking Mexicano: Dynamics of Syncretic Language in Central Mexico. Tucson, Arizona: University of Arizona Press.

Hogan, Jackie. 2003. The social significance of English usage in Japan. Japanese Studies 23: $43-58$.

Holden, Kyril. 1976. Assimilation rates of borrowings and phonological productivity. Language 52: 131-147.

Itô, Junko and Armin Mester. 1999. The structure of the phonological lexicon. In Natsuko Tsujimura (ed.) The Handbook of Japanese Linguistics. Malden, Massachusetts: Blackwell Publishers. 62-100.

Itô, Junko and Armin Mester. 2001. Covert generalizations in Optimality Theory: The role of stratal faithfulness constraints. In The Phonology-Morphology Circle of Korea (ed.) Proceedings of the 2001 International Conference on Phonology and Morphology. Seoul, Korea: Korea Research Foundation. 3-33.

Kang, Yoonjung. 2003. Perceptual similarity in loanword adaptation: English postvocalic word-final stops in Korean. Phonology 20: 219-273.

Labov, William. 1981. Resolving the Neogrammarian controversy. Language 57: 267-308.

Lee, Ponghyung. 2013. The impact of borrowed sounds and neutralization on Korean contrasts: An entropy-driven analysis. Indiana University Linguistic Club Working Papers Online 13.

Lev-Ari, Shiri and Sharon Peperkamp. 2014. An experimental study of the role of social factors in sound change. Laboratory Phonology 5: 379-401.

Natale, Michael. 1975. Convergence of mean vocal intensity in dyadic communication as a function of social desirability. Journal of Personality and Social Psychology 32: 790.

Paradis, Carole and Darlene LaCharité. 1997. Preservation and minimality in loanword adaptation. Journal of Linguistics 33: 379-430.

Pardo, Jennifer S., Rachel Gibbons, Alexandra Suppes and Robert M. Krauss. 2012. Phonetic convergence in college roommates. Journal of Phonetics 40: 190-197.

Peperkamp, Sharon, Inga Vendelin and Kimihiro Nakamura. 2008. On the perceptual origin of loanword adaptations: Experimental evidence from Japanese. Phonology 25: 129-164.

Phillips, Betty S. 2006. Word Frequency and Lexical Diffusion. New York: Palgrave Macmillan. Pierrehumbert, Janet. 2002. Word-specific phonetics. Laboratory Phonology 7: 101-139.

Poplack, Shana and Nathalie Dion. 2012. Myths and facts about loanword development. Language Variation and Change 24: 279-315.

Poplack, Shana and David Sankoff. 1984. Borrowing: The synchrony of integration. Linguistics 22: 99-135. 
Poplack, Shana, David Sankoff and Christopher Miller. 1988. The social correlates and linguistic processes of lexical borrowing and assimilation. Linguistics 26: 47-104.

Putman, William B. and Richard L. Street. 1984. The conception and perception of noncontent speech performance: Implications for speech-accommodation theory. International Journal of the Sociology of Language 46: 97-114.

San Giacomo, Marcela. 2003. Actitudes hacia la lengua producidas al interior de una unidad doméstica náhuatl: Tagcotepec, Sierra Norte de Puebla. Estudio de caso. Unpublished MA thesis. Mexico: Escuela Nacional de Antropología e Historia.

San Giacomo, Marcela. 2009. La présence de l'espagnol en nahuatl: une étude sociolinguistique des adaptations et de la propagation des emprunts. Unpublished Doctoral dissertation. Saint Denis, France: University of Paris 8.

San Giacomo, Marcela. 2011. Habla espontánea y adaptación de préstamos. In Pedro Martín Butragueño (ed.) Realismo en el análisis de corpus orales (I Coloquio de Cambio y Variación Lingüística). México: El Colegio de México. 171-190.

San Giacomo, Marcela and Sharon Peperkamp. 2008. Presencia del español en náhuatl: Estudio sociolingüístico de la adaptación de préstamos. In Maurice Westmoreland and Juan Antonio Thomas (eds.) Selected Proceedings of the Fourth Workshop on Spanish Sociolinguistics. Somerville, Massachusetts: Cascadilla Press. 149-156.

Sebastián-Gallés, Núria and Laura Bosch. 2005. Phonology and bilingualism. In Judith F. Kroll and Annette M. B. de Groot (eds.) Handbook of Bilingualism: Psycholinguistic Approaches. Oxford, U.K.: Oxford University Press. 68-87.

Stemberger, Joseph P. and Brian MacWhinney. 1986. Frequency and the lexical storage of regularly inflected forms. Memory and Cognition 14: 17-26.

T'Sou, Benjamin K. 2001. Language contact and lexical innovation. In Michael Lackner, Iwo Amelung and Joachim Kurtz (eds.) New Terms for New Ideas: Western Knowledge and Lexical Change in Late Imperial China. Leiden, The Netherlands: Brill. 35-56.

Ussishkin, Adam and Andrew Wedel. 2003. Gestural motor programs and the nature of phonotactic restrictions: Evidence from loanword phonology. In Mimu Tsujimura and Gina Garding (eds.) Proceedings of WCCFL 22, 505-518. Somerville, Massachusetts: Cascadilla Press. 505-518.

Uther, Maria, Monja A. Knoll and Denis Burnham. 2007. Do you speak E-NG-L-I-SH? A comparison of foreigner- and infant-directed speech. Speech Communication 49: 2-7.

Vallverdú, Francesc. 1973. El fet linguístic com a fet social: Assaig de linguística institucional. Barcelona, Spain: Edicions 62.

Weinreich, Uriel. 1953. Languages in Contact. The Hauge, The Netherlands: Mouton.

Werker, Janet F. and Richard C. Tees. 1984. Cross-language speech perception: Evidence for perceptual reorganization during the first year of life. Infant Behavior and Development 7: 49-63.

Wiese, Richard. 1996. The Phonology of German. Oxford, U.K.: Clarendon Press.

Winford, Donald. 2005. Contact-induced changes: Classification and processes. Diachronica 22: 373-427.

Wright, Richard A. 2004. Factors of lexical competition in vowel articulation. In John Local, Richard Ogden and Rosalind Temple (eds.) Phonetic Interpretation: Papers in Laboratory Phonology IV. Cambridge, U.K.: Cambridge University Press. 75-87.

Yaeger-Dror, Malcah. 1996. Phonetic evidence for the evolution of lexical classes: The case of a Montreal French vowel shift. In Gregory Guy, Crawford Feagin, Deborah Schiffrin and John Baugh (eds.) Towards a Social Science of Language. Philadelphia, Pennsylvania: Benjamins. 263-287.

(C) 2014 John Wiley \& Sons Ltd 
Zipf, George Kingsley. 1929. Relative frequency as a determinant of phonetic change. Harvard Studies in Classical Philology 40: 1-95.

\section{APPENDIX: Table of adaptation types}

A comprehensive list of all the manners in which each of the foreign consonants was adapted in the dataset, with an example from our dataset for each type of adaptation. Asterisks $\left(^{*}\right)$ indicate that the adaptation was into a segment that is also foreign to Mexicano. Such adaptations were not analyzed.

\begin{tabular}{|c|c|c|c|c|c|}
\hline $\begin{array}{l}\text { Foreign } \\
\text { segment }\end{array}$ & & & $\begin{array}{l}\text { Adaption }(\%) \\
\text { Example word } \\
\text { Pronunciation }\end{array}$ & & \\
\hline \multirow[t]{3}{*}{$/ \beta /$} & $\begin{array}{l}\varnothing(34.8 \%) \\
\text { bicicleta } \\
\text { isikléeta? }\end{array}$ & $\begin{array}{l}\text { /p/ }(27.8 \%) \\
\text { bicicleta } \\
\text { pisiklétəs }\end{array}$ & $\begin{array}{l}/ \mathrm{m} /(12.2 \%) \\
\text { bicicleta } \\
\text { misikléta }\end{array}$ & $\begin{array}{l}\text { /w/ }(4.3 \%) \\
\text { bandera } \\
\text { wandéra }\end{array}$ & $\begin{array}{l}/ \mathrm{h} /(4.3 \%) \\
\text { burro } \\
\text { húro }\end{array}$ \\
\hline & $\begin{array}{l}{ }^{*} / \mathrm{v} /(3.5 \%) \\
\text { burro } \\
\text { vúuroo }\end{array}$ & $\begin{array}{l}* / \mathrm{g} /(2.6 \%) \\
\text { bote } \\
\text { góte }\end{array}$ & $\begin{array}{l}\text { */f/ }(1.7 \%) \\
\text { Burro } \\
\text { fóoro }\end{array}$ & $\begin{array}{l}\text { /t/ }(1.7 \%) \\
\text { bicicleta } \\
\text { tisikléeta }\end{array}$ & $\begin{array}{l}/ \mathrm{l} /(1.7 \%) \\
\text { buche } \\
\text { lút } \int \mathrm{e}\end{array}$ \\
\hline & $\begin{array}{l}\text { */d/ }(1.7 \%) \\
\text { bicicletero } \\
\text { dihletéero? }\end{array}$ & $\begin{array}{l}\text { /k/ }(1.7 \%) \\
\text { burro } \\
\text { kúuro? }\end{array}$ & $\begin{array}{l}\text { /s/ }(0.9 \%) \\
\text { balon } \\
\text { selóon }\end{array}$ & $\begin{array}{l}\text { /j/ }(0.9 \%) \\
\text { bandera } \\
\text { jandéera }\end{array}$ & \\
\hline$/ \mathrm{d} /$ & $\begin{array}{l}\varnothing(46.6 \%) \\
\text { doctora } \\
\text { októrah }\end{array}$ & $\begin{array}{l}/ \mathrm{t} /(24.7 \%) \\
\text { doctora } \\
\text { totóora? }\end{array}$ & $\begin{array}{l}\text { /l/ (19.2\%) } \\
\text { doctora } \\
\text { loktóorah }\end{array}$ & $\begin{array}{l}\text { /g/ }(2.7 \%) \\
\text { compadrito } \\
\text { kompagðíito? }\end{array}$ & $\begin{array}{l}\text { /j/ }(2.7 \%) \\
\text { cadena } \\
\text { kajéenah }\end{array}$ \\
\hline & $\begin{array}{l}\text { / k/ }(1.4 \%) \\
\text { doctora } \\
\text { koktóorah }\end{array}$ & $\begin{array}{l}\text { */ } /(1.4 \%) \\
\text { candado } \\
\text { kandáro? }\end{array}$ & $\begin{array}{l}/ \mathrm{h} /(1.4 \%) \\
\text { amistades } \\
\text { amihtahtsitsis }\end{array}$ & & \\
\hline$/ \mathrm{f} /$ & $\begin{array}{l}/ \mathrm{h} /(47.6 \%) \\
\text { fruta } \\
\text { hrúutah }\end{array}$ & $\begin{array}{l}/ \mathrm{p} /(21.4 \%) \\
\text { fruta } \\
\text { purúutas }\end{array}$ & $\begin{array}{l}\varnothing(14.3 \%) \\
\text { telefono } \\
\text { teléoru? }\end{array}$ & $\begin{array}{l}{ }^{*} / \mathrm{f}^{\mathrm{h}} /(9.5 \%) \\
\text { fruta } \\
\mathrm{f}^{\mathrm{h}} \text { rútareh }\end{array}$ & $\begin{array}{l}\text { /s/ }(4.8 \%) \\
\text { jirafa } \\
\text { kiráasah }\end{array}$ \\
\hline & $\begin{array}{l}{ }^{*} / \gamma /(2.4 \%) \\
\text { fotografia } \\
\text { fotó } \gamma \mathrm{a} \beta \mathrm{ja}\end{array}$ & & & & \\
\hline
\end{tabular}


Appendix (continued)

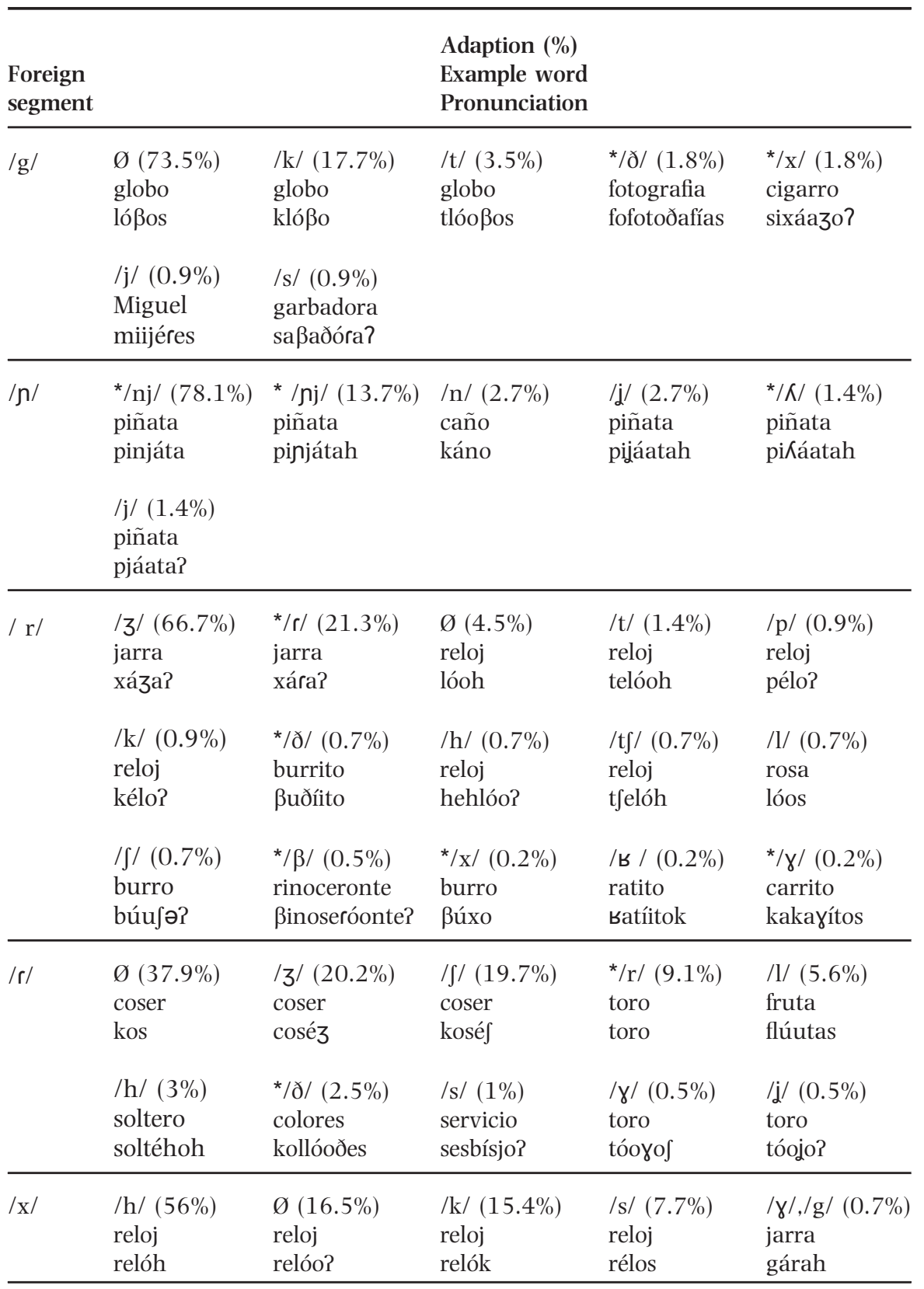


Appendix (continued)

\begin{tabular}{|c|c|c|c|c|c|}
\hline $\begin{array}{l}\text { Foreign } \\
\text { segment }\end{array}$ & & & $\begin{array}{l}\text { Adaption (\%) } \\
\text { Example word } \\
\text { Pronunciation }\end{array}$ & & \\
\hline & $\begin{array}{l}\text { /j/ }(0.7 \%) \\
\text { tijera } \\
\text { tujéera? }\end{array}$ & $\begin{array}{l}/ \mathrm{n} /(0.7 \%) \\
\text { reloj } \\
\text { rélon }\end{array}$ & $\begin{array}{l}/ \mathrm{t} /(0.4 \%) \\
\text { reloj } \\
\text { zelót }\end{array}$ & $\begin{array}{l}/ \mathrm{t} \int /(0.4 \%) \\
\text { Mexico } \\
\text { métjiko? }\end{array}$ & $\begin{array}{l}* / \mathrm{f} /(0.4 \%) \\
\text { reloj } \\
\text { lóor }\end{array}$ \\
\hline & $\begin{array}{l}\text { */ } \beta /(0.4 \%) \\
\text { jarra } \\
\text { báarah }\end{array}$ & $\begin{array}{l}\text { /p/ }(0.4 \%) \\
\text { tijera } \\
\text { tupéeras }\end{array}$ & $\begin{array}{l}/ \mathrm{j} /(0.4 \%) \\
\text { Mexicano } \\
\text { mejcáno }\end{array}$ & & \\
\hline
\end{tabular}

Address correspondence to:

Shiri Lev-Ari Max Planck Institute for Psycholinguistics Wundtlaan 1 Nijmegen $6525 \mathrm{XD}$ The Netherlands shirilevari@gmail.com 